\title{
The Learning Method of Peer Review in College English Writing Course
}

\author{
https://doi.org/10.3991/ijet.v15i05.13775 \\ Hua Sun \\ Beijing University of Civil Engineering and Architecture, Beijing, China \\ Esther1971@126.com
}

\begin{abstract}
Peer review is an important teaching method of writing. College English has a large vocabulary, complex situations and high degree of specialization, which are difficult points in teaching. Through peer review, students can benefit a lot, such as enhancing interest in college English reading and writing through the exchange of reading and evaluation, enhancing initiative in writing and improving their abilities to identify errors and appreciate English articles. In this paper, the applications of the learning method of peer review in college English teaching were investigated, and it was found that teacher's behavior, time arrangement and student's behavior were all particularly important and needed to be arranged in a scientific way. On the other hand, a student-oriented teaching model of "trinity" was also presented, which covered three target elements: ability, knowledge and education. In this paper, a fuzzy comprehensive evaluation method was used to evaluate the learning outcomes of peer review, and an evaluation indicator system for students' learning ability and the weights thereof were established. According to the actual situation of the evaluated objects, four evaluation grades were selected, that is, excellent, good, fair and poor. Our teaching experiment showed that through this learning model, students have improved their English writing ability and reading comprehension ability to a certain degree, as well as their self-learning ability, which is beneficial to the consolidation of their learning effect.
\end{abstract}

Keywords-The learning method of peer review; English writing course; application effect; trinity

\section{Introduction}

College English teaching is characterized by strong specialization and large vocabulary, etc., and many college English teachers have realized the defects of traditional teaching mode. Difficulties in English writing teaching come in close succession and the combination of the modern teaching model and teaching of English writing has attracted widespread attention. English writing is always an indispensable part of English teaching, and an important embodiment of students' English learning effect. It plays an important role in whether students can become international talents [1]. In modern college English teaching, teachers have 
extensively adopted the teaching model of peer review in writing teaching, stepped up the construction of flipped classroom, stimulated and improved students' interest in reading [2], and lower the difficulty and stress in their correction of compositions. Peer review is of irreplaceable significance and value for comprehensively promoting college students' English article comprehension ability and English paper writing ability, easing the burden of college teachers in English writing teaching, promoting the teaching reform and cultivating more international professionals.

However, at present, there are still more or less problems with the application of peer review in the writing teaching of English majors in China, including insufficient experience of teachers, traditional teaching strategies, imperfect review mechanism and procedures and inadequate follow-up of review results, which will probably affect the teaching quality [3]. For this reason, the application of peer review in English writing under the mode of flipped classroom has become an important subject facing English writing teaching.

In this paper, research was conducted in such a way that closely combined the innovation of English writing teaching and the advantages of traditional teaching of English writing. On the basis of traditional research philosophy and teaching methods, it mainly made the following innovations: first of all, it created a new "trinity" model, around students' autonomous learning ability; secondly, it constructed evaluation on students' autonomous ability; thirdly, it combined peer review with MOOC. Hopefully, through full combination of modern teaching model of peer review and modern teaching ideas and tools, the teaching of language writing in our country can be greatly promoted as a whole.

\section{State of the Art}

English writing is a comprehensive reflection of students' English level, and also an important point and difficult point in the English teaching in Chins. There are many researches and practices on the teaching methods of English writing in China, and the teaching model of peer review has thus been widely applied in English writing teaching of colleges and universities in China. In view of the teaching model of peer review in English writing, an education researcher in China points out that the main ideas with which students write English paper mainly originate from their teachers' guidance. Teachers are the only evaluators of compositions and the evaluation form is single. As a result, students have strong dependence on their teachers, but low interest in writing [4]. Peer review is an effective teaching strategy for English writing. There are many researches in this regard in China with different focuses, but the results are mostly smattering and brief [5]. Generally speaking, the researches in China are still in the infancy. There are many theories, but relatively few practices.

Through a study on the teaching and effect evaluation of language writing, Saito concluded that in teaching activities based on peer review, good students made relatively slow progress, while poor students made relatively rapid progress [6]. On the other hand, the evaluation criteria of students were somewhat subjective and it was especially important to clarify the evaluation criteria and scoring points. Also, it 
is important to assess the evaluation results of students every time. Tsukada et al. carried out a survey on students' attitude towards peer review and found that students were positive in the evaluation of others, but passive towards others' reviews to a certain extent [7]. Many students disapproved of peer review, and dismissed the classmates' reviews as inappropriate. On the other hand, studies on the validity of the learning method of peer review and on the validity of peer review, especially concurrent validity, consequential validity and reliability, have also received widespread attention from foreign researchers. For peer review, the evaluation ability of fellow students is an important criterion. After long-term study, Freeman et al. concluded that after clear evaluation rules of peer review were set up, teaching practice showed that the consistency between teacher review and peer review was relatively high, and such a teaching method can improve students' learning efficiency [8].

Although theoretically, peer review has numerous advantages for teaching, while improving the learning effect of learners, peer review also costs learners more time and increases their burden in learning. Additionally, there is a lack of objective evaluation. As a result, the validity cannot be effectively guaranteed, though the feedback effect of teaching is improved. For this reason, taking the course College English Writing as an example, the present study explores the application effect of peer review in language teaching from the perspective of actual application, with a view to gain an all-round understanding of its advantages and disadvantages.

\section{The Specific Form of the Applications of Peer Review in College English Writing course}

\subsection{The learning method of peer review}

The learning method of peer review means that people with the same learning goal and status help and support each other and organize learning at regular intervals, in order to acquire more professional skills [9]. At present, it has been widely valued and investigated as an important means and link in the pedagogics of various courses and also an important link in writing teaching methods. The learning method of peer review plays an irreplaceable and positive role in improving students' language competence [10]. However, throughout English writing in colleges and universities in China, the effect of peer review teaching strategy is not very satisfactory, and the teaching results are uneven. Through a case analysis of the teaching model of peer review in China's English writing teaching, we can easily find that this is mainly due to the differences and deficiencies of teaching procedures. An effective English writing peer review teaching strategy should be carried out based on the following procedures. 


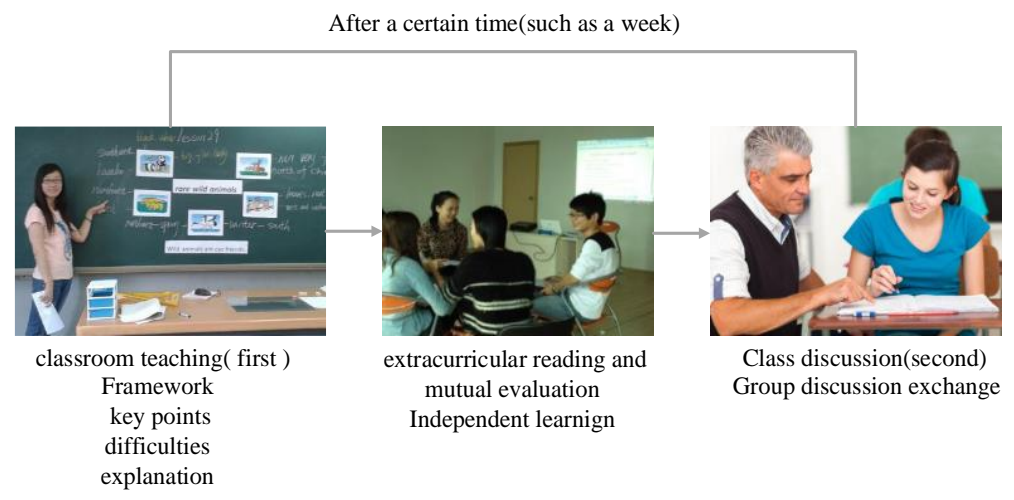

Fig. 1. The Procedures of the Learning Method of Peer Review

From the above basic procedures, it can be seen that that first of all, teachers should teach English courses and assign reading and writing tasks for students, in combination with the teaching contents in classroom. Secondly, according to the teaching content of the current lesson, teachers should provide key point analysis, writing tips and evaluation criteria for reference for writing exercise. Thirdly, for the peer review of students, peers are selected randomly. Authentic and direct comments are given to English writings. Based on teachers' guidance, scientific, reasonable, objective and true peer review is guaranteed for students. Fourthly, the teachers review, make comments and guide students to self-examine. Through the practice of peer review for many times, it is not hard to find that a vast majority of students gradually notice the format, language expression and other details that are easily ignored by their peers in English writing, and further reflect on and introspect the shortcomings and omissions in their own writings.

Teacher behavior

Time distribution

Student behavior

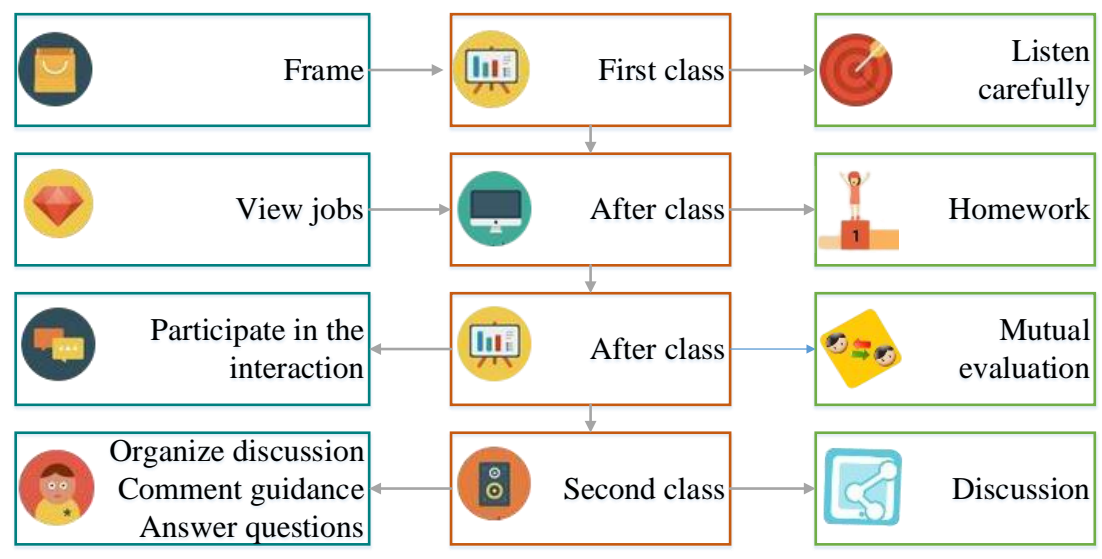

Fig. 2. Different Roles and Time Periods of the Learning Method of Peer Review 
In English writing teaching activities based on peer review, teacher's behavior, time arrangement and student's behavior are all particularly important and need to be arranged in a scientific way. As shown in Fig. 2, teachers should be able to describe the requirements and framework of English writing, guide English reading and writing, throw out suggestions, review the results of peer review, and improve the accuracy of peer review and draw students' attention, take part in interaction, organize discussion, make comments, guide and disabuse at appropriate time nodes. In teaching activities based on peer review, the main time nodes are: the first classroom teaching, extracurricular reading, extracurricular reading and writing, and the second classroom teaching. When teachers respond to different times, students are supposed to listen carefully in class, finish assignments, review each other objectively, and be involved in discussion and reflection at different time nodes. The teaching effect can be improved through planned teaching and learning activities at different time nodes.

\section{2 "Trinity" class based on peer review}

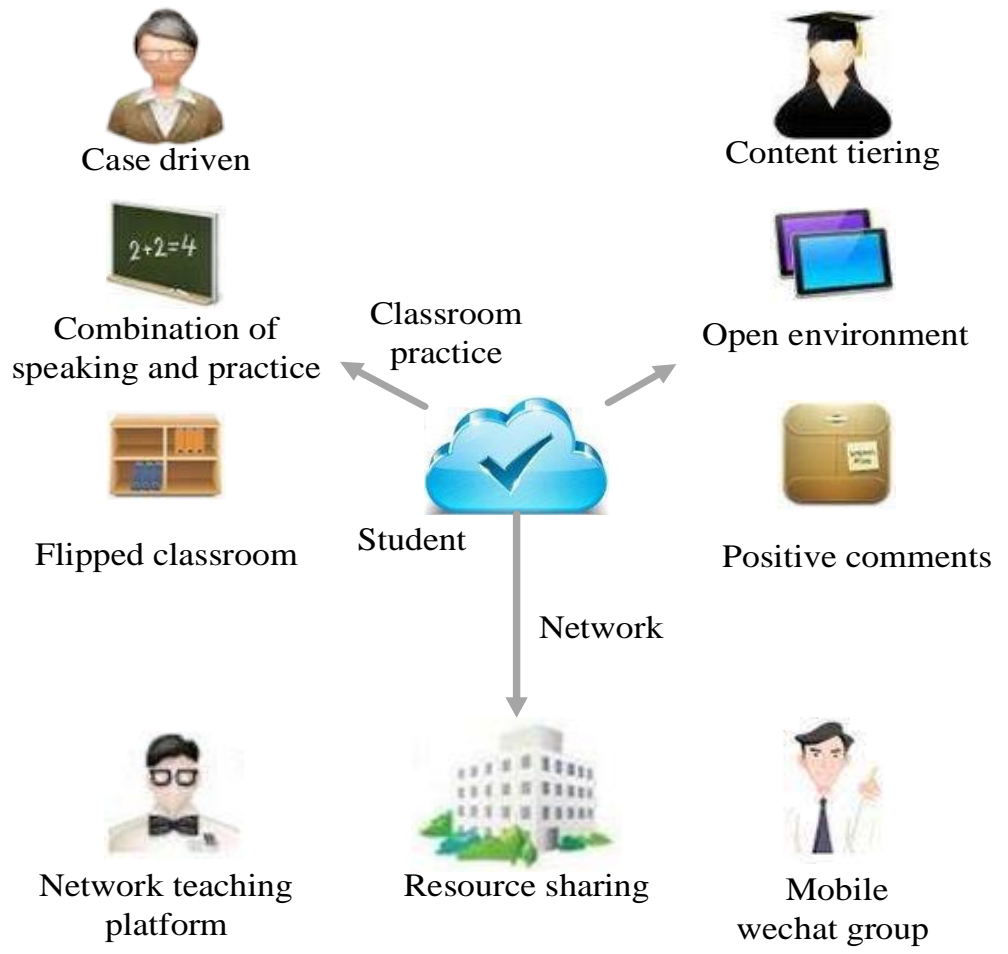

Fig. 3. The Teaching Model of Trinity

Currently, the teaching model of trinity mainly aims at three aspects: ability, knowledge, education, and MOOC offers more possibilities for trinity teaching. From 
actual teaching practice, the teaching model of trinity mainly focuses on students and is divided into the following two aspects:

Classroom practice: In teaching practice, the traditional teaching model is broken through, and an experimental teaching model featured by "hierarchical contents, open environment and positive evaluation" is adopted. Hierarchical contents mean that experimental contents are divided into three levels: basic experiment, expanded experiment and innovative experiment. Students are made to learn extracurricular knowledge and give peer review, based on classroom knowledge and focus on the knowledge learned in English class, under the teachers' guidance. The class is given back to the students, so that they can have the opportunity to learn spontaneously and take the initiative to speak and discuss. Meanwhile, the teaching model of flipped classroom is also introduced, so that the precious time in class can be made full use of and the teaching of knowledge framework, important points and difficult points, etc. can be reinforced. The teachers should step up guidance on students' learning, let students consolidate learning effect in their spare time, cultivate their autonomous learning ability, make them build up confidence in learning, be the master of learning, and further improve their learning enthusiasm.

E-learning: With the rapid development of social science and technology, more possibilities are offered for the e-learning of students. In English writing teaching process based on peer review, the advantages of network resources should be brought into fully play, so as to promote the students' learning effect and the teachers' teaching effect. Broadly speaking, it has the following advantages: first of all, there are abundant network resources and a lot of learning and teaching materials can be downloaded through the Internet. Secondly, it is helpful for homework management and can ensure the high efficiency of English composition submission and evaluation. Thirdly, intelligent grading can be achieved. Teachers can ask students to submit compositions and assignments by themselves through the Internet. While teachers make comments and students review each other, online grading software can also give scores for students' English writings, so that students can draw on evaluations more extensively and gain all-round improvement. Fig. 4 shows a screenshot of a students' e-learning in an English literature database. Fig. 5 shows a scene in which students review and correct compositions for each other through a network platform. 


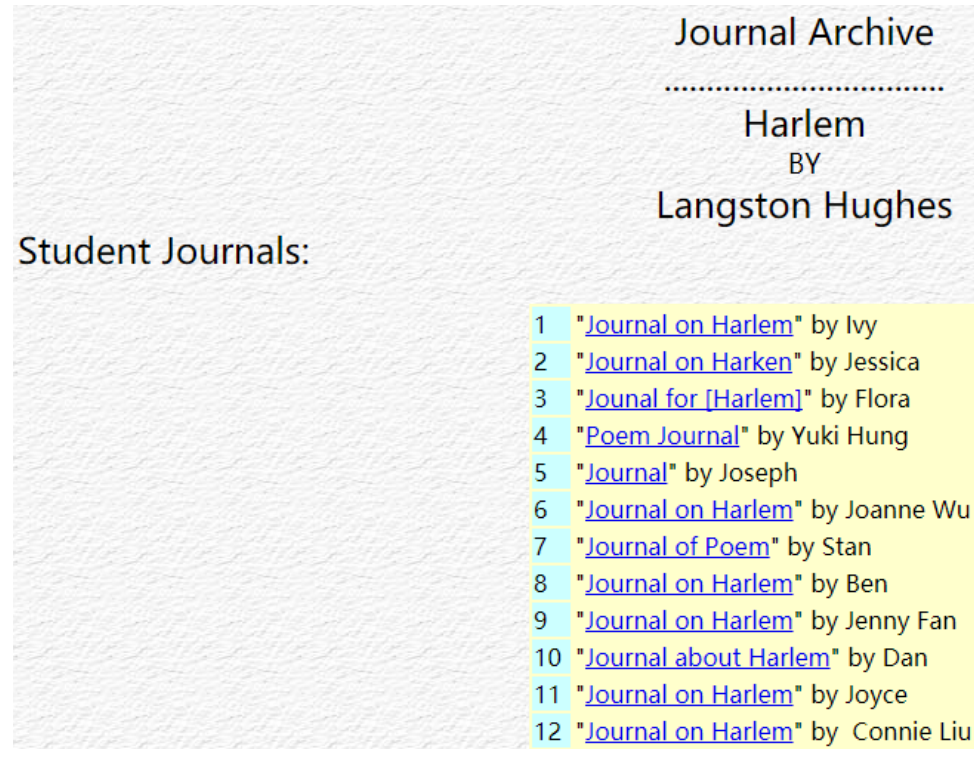

Fig. 4. Screenshot of E-learning based on Peer Review

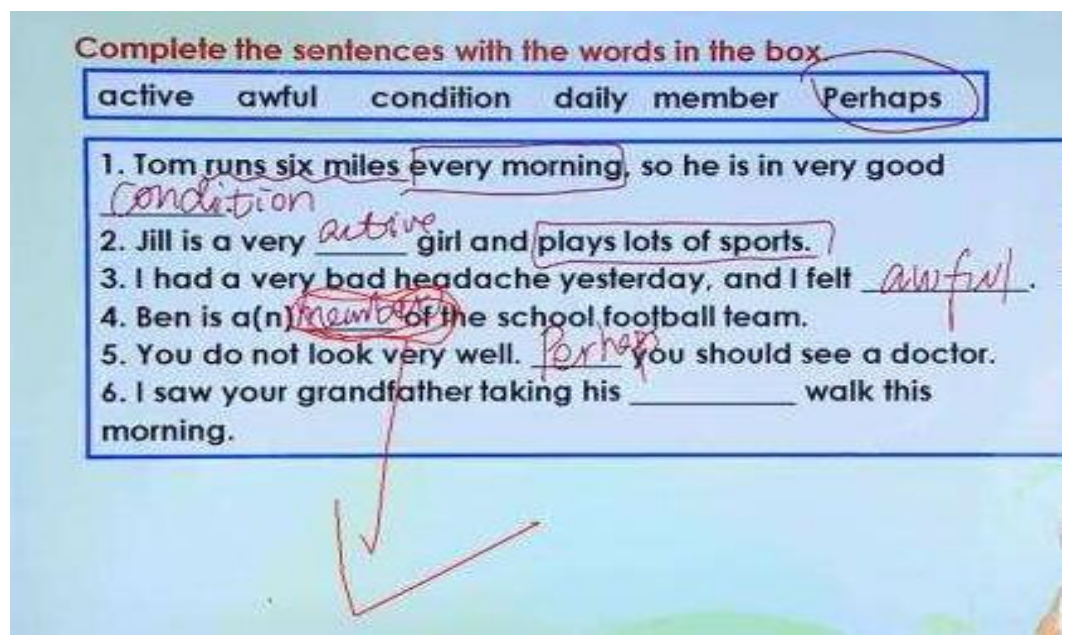

Fig. 5. Students Review and Correct Compositions for Each Other Through a Network Platform

From Figs. 4 and 5, it can be seen that with the discussion area, students can communicate and achieve growth in the discussion area. They can also practice and learn online, the massive question bank can help them take mock tests, and the school can also launch English composition challenges and other activities, through the course link of MOOC or quality English learning websites, in order to educate through entertainment, help students grow in entertainment and provide them with a large quantity of English knowledge or expand their existing knowledge. 


\subsection{The evaluation of students' autonomous learning ability based on peer review}

In this paper, a fuzzy comprehensive evaluation method was used to evaluate the learning outcomes of peer review. The main evaluation steps are as follows:

Step 1: U was defined as the set of evaluation indicators and $V$ as the set of comments.

The set of evaluation indicators included $\mathrm{m}$ evaluation indicators:

$$
U=\left\{u_{1}, u_{2}, \ldots, u_{n}\right\}
$$

The set of comments included $n$ levels of evaluation indicators:

$$
V=\left\{v_{1}, v_{2}, \ldots, v_{m}\right\}
$$

Each level can correspond to a fuzzy subset;

Step 2: The weight vectors of the evaluation indicators were determined.

After the set of evaluation indicators and set of comments were determined, it was also needed to determine the weight vectors of evaluation indicators, that is, $W=\left\{w_{1}, w_{2}, \ldots, w_{m}\right\}$, where wi in the weight vectors was the degree of membership of element ui in the fuzzy subset. The following formula should be satisfied:

$$
\sum_{i=1}^{m} I, w_{i} \geq 0, i=1,2, \ldots, m
$$

Step 3: A fuzzy relation matrix $R$ was set up.

The evaluated object was quantified from the evaluation elements $u_{i}(i=1,2, \ldots, m)$, that is, the degree of membership of the evaluated object in the set of comments, $\mathrm{V}$ was determined at the level of single factor, and the following fuzzy relation matrix was obtained:

$$
R=\left[\begin{array}{cccc}
r_{1,1} & r_{1,2} & \ldots & r_{1, n} \\
r_{2,1} & r_{2,2} & \ldots & r_{2, n} \\
\ldots & \ldots & \ldots & \ldots \\
r_{n, 1} & r_{n, 2} & \ldots & r_{n, n}
\end{array}\right]
$$

In the matrix $\mathrm{R}$, the element in the ith row and the jth column was $r_{i j}(i=1,2, \ldots, m ; j=1,2, \ldots, n)$, where the performance of an object through a certain element Ui was characterized by multiple indicator values of the fuzzy quantifier Ri.

Step 4: The fuzzy evaluation vector $\mathrm{P}$ of the evaluated object was calculated. The calculation formula was as follows: 


$$
P=\left(p_{1}, p_{2}, \ldots, p_{m}\right)=W \cdot R=\left(w_{1}, w_{2}, \ldots, w_{m}\right) \cdot\left[\begin{array}{cccc}
r_{1,1} & r_{1,2} & \ldots & r_{1, n} \\
r_{2,1} & r_{2,2} & \ldots & r_{2, n} \\
\ldots & \ldots & \ldots & \ldots \\
r_{m, 1} & r_{m, 2} & \ldots & r_{m, n}
\end{array}\right]
$$

Step 5: The fuzzy evaluation vector $P$ was analyzed.

The fuzzy evaluation vector $\mathrm{P}$ was normalized for the purpose of analysis and evaluation and the final score is obtained.

According to the above steps, an evaluation indicator system for students' learning ability and the weights thereof were established using the expert grading method. For details, see Tab. 1:

Table 1. The Evaluation Indicator System for Students' Learning Ability And the Weights Thereof

\begin{tabular}{|c|c|c|c|c|}
\hline $\begin{array}{l}\text { Objective } \\
\text { Layer A }\end{array}$ & \multicolumn{2}{|c|}{$\begin{array}{c}\text { Primary Evaluation } \\
\text { Indicators B }\end{array}$} & \multicolumn{2}{|l|}{$\begin{array}{c}\text { Secondary Evaluation } \\
\text { Indicators C } \\
\end{array}$} \\
\hline \multirow{9}{*}{$\begin{array}{l}\text { Students' } \\
\text { Autonomous } \\
\text { Learning } \\
\text { Ability }\end{array}$} & Evaluation Element & Weight & Evaluation Element & Weight \\
\hline & \multirow{5}{*}{ Autonomous Ability B1 } & & Learning motivation $\mathrm{C} 1$ & \\
\hline & & & Learning initiative C2 & \\
\hline & & & Learning habit $\mathrm{C} 3$ & \\
\hline & & & $\begin{array}{l}\text { The ability to manage and control } \\
\text { oneself } \mathrm{C} 4\end{array}$ & \\
\hline & & & $\begin{array}{l}\text { The ability to set learning goals and } \\
\text { plans C5 }\end{array}$ & \\
\hline & \multirow{3}{*}{ Learning Ability B2 } & & Learning method C6 & \\
\hline & & & $\begin{array}{l}\text { The ability to acquire knowledge and } \\
\text { discover problems C7 }\end{array}$ & \\
\hline & & & $\begin{array}{l}\text { The ability to solve problems and apply } \\
\text { knowledge C8 }\end{array}$ & \\
\hline
\end{tabular}

With respect to the above indicators of autonomic learning, an evaluation team was set up, which was mainly composed of several roles, including college English teachers, instructors, counselors and classmates, etc. who participated in the evaluation of students. During the evaluation, the members of the evaluation team examined and rated evaluated objects in terms of the secondary evaluation indicators $\mathrm{C}$ one by one, and selected four grades, that is, excellent, good, fair and poor, according to the actual conditions of evaluated objects. The specific evaluation is shown in Tab. 2: 
Table 2. Summary Table of the Evaluation Data of Secondary Evaluation Indicators $C$ of English Writing Ability in a Given College

\begin{tabular}{|c|c|c|c|c|c|}
\hline \multirow{2}{*}{\begin{tabular}{|c|} 
Primary \\
Evaluation \\
Indicators B \\
Evaluation \\
Element
\end{tabular}} & \multirow{2}{*}{$\begin{array}{c}\text { Secondary Evaluation Indicators C } \\
\text { Evaluation Element }\end{array}$} & \multicolumn{4}{|c|}{ Grade } \\
\hline & & Excellent & Good & Fair & Poor \\
\hline \multirow{4}{*}{$\begin{array}{l}\text { Autonomous } \\
\text { Ability B1 }\end{array}$} & Learning motivation $\mathrm{C} 1$ & 0.250 & 0.600 & 0.150 & 0.000 \\
\hline & Learning initiative $\mathrm{C} 2$ & 0.300 & 0.567 & 0.133 & 0.000 \\
\hline & Learning habit C3 & 0.167 & 0.333 & 0.450 & 0.050 \\
\hline & The ability to manage and control oneself $\mathrm{C} 4$ & 0.033 & 0.300 & 0.400 & 0.267 \\
\hline \multirow{4}{*}{$\begin{array}{l}\text { Learning Ability } \\
\text { B2 }\end{array}$} & The ability to set learning goals and plans C5 & 0.083 & 0.350 & 0.317 & 0.250 \\
\hline & Learning method C6 & 0.117 & 0.283 & 0.383 & 0.217 \\
\hline & $\begin{array}{l}\text { The ability to acquire knowledge and discover } \\
\text { problems C7 }\end{array}$ & 0.050 & 0.183 & 0.484 & 0.283 \\
\hline & $\begin{array}{l}\text { The ability to solve problems and apply } \\
\text { knowledge C } 8\end{array}$ & 0.100 & 0.317 & 0.350 & 0.233 \\
\hline \multirow{3}{*}{$\begin{array}{l}\text { Learning } \\
\text { evaluation and } \\
\text { effect B3 }\end{array}$} & Self-feedback and check of learning effect C9 & 0.117 & 0.267 & 0.518 & 0.100 \\
\hline & Utilization of learning resources $\mathrm{C} 10$ & 0.300 & 0.433 & 0.267 & 0.000 \\
\hline & Collaborative learning C11 & 0.183 & 0.367 & 0.433 & 0.017 \\
\hline
\end{tabular}

Based on the above evaluation and selection method, the following formula was adopted to obtain data in Tab. 2:

Tab. 1 is a basic evaluation model, so after the completion of secondary evaluation indicators $\mathrm{C}$, it was necessary to obtain evaluation results through calculation and complete the evaluation of primary evaluation indicators B. From Tab. 2, it can be seen that the evaluation matrices corresponding to autonomic ability B1, learning ability B2, learning evaluation and effect B3 should be R1, R2 and R3, respectively.

Where

$$
R_{1}=\left[\begin{array}{llll}
0.250 & 0.600 & 0.150 & 0.000 \\
0.300 & 0.567 & 0.133 & 0.000 \\
0.167 & 0.333 & 0.450 & 0.050 \\
0.330 & 0.300 & 0.400 & 0.267
\end{array}\right]
$$

Accordingly, $W_{1}=(0.312,0.386,0.184,0.118)$

Where

$$
R_{2}=\left[\begin{array}{llll}
0.083 & 0.035 & 0.317 & 0.250 \\
0.117 & 0.283 & 0.383 & 0.217 \\
0.050 & 0.183 & 0.484 & 0.283 \\
0.100 & 0.317 & 0.350 & 0.233
\end{array}\right]
$$

Accordingly, $W_{2}=(0.367,0.149,0.351,0.133)$

Where 


$$
R_{3}=\left[\begin{array}{llll}
0.117 & 0.267 & 0.518 & 0.100 \\
0.300 & 0.433 & 0.267 & 0.000 \\
0.183 & 0.367 & 0.433 & 0.017
\end{array}\right]
$$

Accordingly, $W_{3}=(0.411,0.307,0.282)$

After the calculation above, R1, R2 and R3 corresponding to autonomic ability B1, learning ability B2, learning evaluation and effect B3 respectively were obtained as follows:

$$
\begin{aligned}
& P_{1}=W_{1} R_{1}=(0.312,0.386,0.184,0.118)\left[\begin{array}{llll}
0.250 & 0.600 & 0.150 & 0.000 \\
0.300 & 0.567 & 0.133 & 0.000 \\
0.167 & 0.333 & 0.450 & 0.050 \\
0.330 & 0.300 & 0.400 & 0.267
\end{array}\right]=(0.228,0.503,0.228,0.041) \\
& P_{2}=W_{2} R_{2}=(0.367,0.149,0.351,0.133)\left[\begin{array}{llll}
0.083 & 0.035 & 0.317 & 0.250 \\
0.117 & 0.283 & 0.383 & 0.217 \\
0.050 & 0.183 & 0.484 & 0.283 \\
0.100 & 0.317 & 0.370 & 0.233
\end{array}\right]=(0.079,0.277,0.390,0.254) \\
& P_{3}=W_{3} R_{3}=(0.411,0.307,0.282)\left[\begin{array}{llll}
0.117 & 0.267 & 0.518 & 0.100 \\
0.300 & 0.433 & 0.267 & 0.000 \\
0.183 & 0.367 & 0.433 & 0.017
\end{array}\right]=(0.192,0.346,0.416,0.046)
\end{aligned}
$$

Again, a comprehensive evaluation was carried out in view of the objective layer A. Based on three definite vectors, R1, R2 and R3, corresponding to autonomic ability $\mathrm{B} 1$, learning ability $\mathrm{B} 2$, learning evaluation and effect B3, a comprehensive evaluation matrix $\mathrm{R}$ was derived, and the evaluation results are as follows:

$$
R=\left[\begin{array}{l}
p_{1} \\
p_{2} \\
p_{3}
\end{array}\right]=\left[\begin{array}{llll}
0.228 & 0.503 & 0.228 & 0.041 \\
0.079 & 0.227 & 0.390 & 0.254 \\
0.192 & 0.346 & 0.416 & 0.046
\end{array}\right]
$$

Where $W=(0.405,0.378,0.217)$

Finally, the value of $\mathrm{P}$ was calculated, and the final comprehensive evaluation results are as follows:

$$
P=W \cdot R=(0.405,0.378,0.217)\left[\begin{array}{cccc}
0.228 & 0.503 & 0.228 & 0.041 \\
0.079 & 0.227 & 0.390 & 0.254 \\
0.192 & 0.346 & 0.416 & 0.046
\end{array}\right]
$$

Where $^{W}=(0.164,0.384,0.330,0.122)$ 
According to the final results above, excellent students accounted for $16.9 \%$, good students for $38.9 \%$, fair students for $31.9 \%$ and poor students for $12.3 \%$.

\section{$4 \quad$ Teaching Example and Effect}

\subsection{Teaching example}

College English compositions were reviewed with the above calculation method of peer review. During the review, it was guaranteed that each composition of the student received at least 3 reviews and each student reviewed at least 5 compositions, so that the calculation system can get the final score. At this point, the teachers further evaluated and commented on students' English compositions. The calculation method is shown in Tab. 3:

Table 3. Calculation Method of Students' Final Score

\begin{tabular}{|l|l|}
\hline \multicolumn{1}{|c|}{ Completion Degree of Peer Review } & \multicolumn{1}{c|}{ Final Score } \\
\hline Completed all of the peer review & Total score of student's homework $* 100 \%$ \\
\hline Not completed all of the peer review & Total score of student's homework *80\% \\
\hline Not participated in the peer review & Total score of student's homework $* 50 \%$ \\
\hline
\end{tabular}

** Significantly correlated at the level of. 01 (two-tailed).

After the above evaluation results were obtained, the English composition scores of 115 students were reviewed. Since English reading ability can directly improve students' English composition writing ability, the author made a comparison from two aspects, that is, students' English reading ability and English writing ability, and got the correlation analysis among English reading ability, English composition writing ability, exam result, and peer review result, as shown in Tabs. 4 and 5 below:

Table 4. Correlation between Exam Result and Single Peer Review Result (English Reading Ability) $(\mathrm{n}=100)$

\begin{tabular}{|l|c|c|c|c|c|c|c|c|}
\hline & $\mathbf{1}$ & $\mathbf{2}$ & $\mathbf{3}$ & $\mathbf{4}$ & $\mathbf{5}$ & $\mathbf{6}$ & $\mathbf{7}$ & $\mathbf{8}$ \\
\hline Pearson Correlation & 0.121 & $0.319^{* *}$ & $0.348^{* *}$ & $0.527 * *$ & $0.327 * *$ & $0.357 * *$ & 0.089 & $0.325 * *$ \\
\hline $\mathrm{P}$ & 0.23 & 0.001 & 0.000 & 0.000 & 0.001 & 0.000 & 0.379 & 0.001 \\
\hline
\end{tabular}

Table 5. Correlation between Exam Result and Single Peer Review Result (English Writing Ability) $(\mathrm{n}=100)$

\begin{tabular}{|l|c|c|c|c|c|c|c|c|c|}
\hline & $\mathbf{1}$ & $\mathbf{2}$ & $\mathbf{3}$ & $\mathbf{4}$ & $\mathbf{5}$ & $\mathbf{6}$ & $\mathbf{7}$ & $\mathbf{8}$ & $\mathbf{9}$ \\
\hline Pearson Correlation & $0.243 *$ & $0.308 * *$ & 0.257 & $0.244^{*}$ & $0.261 * *$ & $0.346 * *$ & $0.339 * *$ & $0.241 *$ & 0.262 \\
\hline P & 0.015 & 0.002 & 0.01 & 0.014 & 0.009 & 0.000 & 0.001 & 0.016 & 0.008 \\
\hline
\end{tabular}

* Significantly correlated at the level of 0.05 (two-tailed). ** Significantly correlated at the level of .01 (two-tailed).

Based on the analysis of data packets in Tabs. 4 and 5, it was found that there was certain correlation between exam result and students' peer review, but the correlation was not very high. So the correlation between peer review and exam result was 
further analyzed and Tab. 6 was derived, so as to further verify the correlation between the two.

Table 6. Correlation Analysis between Exam Result and Peer Review Result(n=100)

\begin{tabular}{|l|c|c|}
\hline & Average Score of English Reading & Average Score of English Writing \\
\hline Pearson Correlation & $0.469^{* *}$ & $0.389^{* *}$ \\
\hline $\mathrm{p}$ & 0 & 0 \\
\hline
\end{tabular}

** Significantly correlated at the level of .01 (two-tailed).

\subsection{Teaching effect}

The research objects of this paper were students attending the English writing course in the class of 2019 in a certain college. English writing activities based on peer review were carried out and 115 students participated in the activities. With this learning model, 97 students had improved their English writing ability and reading comprehension ability to a certain degree. The "improved" here meant that their exam results were promoted, and the proportion was $84.35 \%$. Meanwhile, they had also enhanced their self-learning ability. As shown in Tab. 7, students' abilities had been improved in terms of learning motivation, learning initiative, learning habit, the ability to manage and control oneself, the ability to set learning goals and plans, and learning method. And their abilities in terms of the ability to acquire knowledge and discover problems, the ability to solve problems and apply knowledge, self-feedback and check of learning effect, utilization of learning resources and collaborative learning had also been enhanced. In conclusion, while promoting students' English writing and reading abilities, peer review also provides a guarantee for students' continuous improvement and growth in the future.

Table 7. Statistical Table of Students' Average Scores of Various Abilities of English Writing

\begin{tabular}{|l|c|}
\hline \multicolumn{1}{|c|}{ Item } & Score \\
\hline Learning motivation C1 & $4.54 \pm 0.34$ \\
\hline Learning initiative C2 & $5.52 \pm 0.36$ \\
\hline Learning habit C3 & $4.60 \pm 0.32$ \\
\hline The ability to manage and control oneself C4 & $4.65 \pm 0.36$ \\
\hline The ability to set learning goals and plans C5 & $4.52 \pm 0.37$ \\
\hline Learning method C6 & $4.50 \pm 0.38$ \\
\hline The ability to acquire knowledge and find problems C7 & $4.15 \pm 0.42$ \\
\hline The ability to solve problems and apply knowledge C8 & $4.10 \pm 0.36$ \\
\hline Self-feedback and check of learning effect C9 & $4.11 \pm 0.43$ \\
\hline Utilization of learning resources C10 & $3.09 \pm 0.43$ \\
\hline Collaborative learning C11 & $4.09 \pm 0.32$ \\
\hline
\end{tabular}




\section{Conclusion}

To sum up, it is necessary to apply peer review in college English writing classes. First of all, through data analysis, it is learned that both single peer review result and average score are correlated to exam results to a certain extent and can be reflected through peer scoring. Peer review is a formative assessment strategy, and compared with traditional one-off summative assessment, formative assessment can better reflect students' learning attitude at ordinary times. Secondly, it is implicated that we should make full use of modern teaching strategies. For example, in the present study, the 3D teaching method of "trinity" is combined with the learning method of peer review. At the same time, it is necessary to create an evaluation model for peer review and constantly update the teaching schedule and teaching content, according to this evaluation model, which is more beneficial to the improvement of teaching effect. In subsequent studies, we will continue to improve this model. Secondly, in the present study, we find that teachers need to keep homework requirements consistent with the evaluation criteria, so as to ensure the effectiveness of peer review. Also, we need to clarify the methods and significance of peer review, to avoid students' resistance psychology, and enhance the effectiveness of peer review. We should encourage everyone to participate in the refinement of peer review and improve the awareness of participants. In a word, traditional teaching model can no longer satisfy the needs of modern English learning, and we should strengthen its combination with modern teaching strategies. Peer review is an effective way to improve college students' English composition level, and should be constantly refined through ongoing teaching practice.

\section{References}

[1] Zhang, E.W., Zhang, W.M., Jin, C.X. SPOC-based Flipped Classroom of College English: Construction of an Effective Learning Model. International Journal of Emerging Technologies in Learning, 2018, vol. 13(1), pp. 37-45. https://doi.org/10.3991/ijet.v13i01.7 $\underline{513}$

[2] Yang, Y. An English Translation Teaching Model Based on Interactive Reading Theory. International Journal of Emerging Technologies in Learning, 2018, vol. 13(08), pp. 146158. https://doi.org/10.3991/ijet.v13i08.9047

[3] Teeter, J. Deconstructing attitudes towards plagiarism of Japanese undergraduates in EFL academic writing classes. English Language Teaching,2015, vol. 8(1), pp. 95-109. https:// doi.org/10.5539/elt.v8n1p95

[4] He, X.Y. An action research on improving non-english majors' english writing by basic sentence pattern translation drills. English Language Teaching, 2015, vol. 9(1), pp. 142147. https://doi.org/10.5539/elt.v9n1p142

[5] Zhang, X., \& McEneaney, J. E. What Is the Influence of Peer Feedback and Author Response on Chinese University Students' English Writing Performance?. Reading Research Quarterly, 2020, vol. 55(1), pp. 123-146. https://doi.org/10.1002/rrq.259

[6] Saito, H. EFL classroom peer assessment: training effects on rating and commenting. Language Testing, Language Testing, 2008, vol. 25(4), pp. 553-581. https://doi.org/10.11 $\underline{77 / 0265532208094276}$ 
[7] Tsukada, K., Birdsong, D., Mack, M., Sung, H., Bialystok, E., \& Flege, J. Release bursts in english word-final voiceless stops produced by native english and korean adults and children. Phonetica, 2004, vol. 61(2-3), pp. 67-83. https://doi.org/10.1159/000082557

[8] Freeman, S.R., Greene, R.E., Kimball, A.B., Freiman, A., Barzilai, D.A., \& Muller, S., et al. US dermatology residents' satisfaction with training and mentoring: survey results from the 2005 and 2006 Las Vegas Dermatology Seminars. Archives of dermatology, 2008, vol. 144(7), pp. 896-900. https://doi.org/10.1001/archderm.144.7.896

[9] Crowe, J. A., Silva, T., \& Ceresola, R. The effect of peer review on student learning outcomes in a research methods course. Teaching Sociology, 2015, vol. 43(3), pp. 201213. https://doi.org/10.1177/0092055X15578033

[10] Daskalovska, N., Ulanska, T., \& Hadzi-Nikolova, A. The Effects of Explicit Supplemental Instruction on Students' Language Competence. Knowledge - International Journal, 2019, vol. 30(5), pp. 1151-1156.

\section{$7 \quad$ Author}

Hua Sun is a lecturer in the Beijing University of Civil Engineering and Architecture, Beijing, China (Esther1971@126.com).

Article submitted 2020-01-15. Resubmitted 2020-02-20. Final acceptance 2020-02-20. Final version published as submitted by the authors. 